P-ISSN: 2615-2851 E-ISSN: 2622-7622

Volume 5

Issue 1

(63-71)

July 2021

GHIDZA : JURNAL GIZI DAN KESEHATAN

RESEARCH ARTICLE

DOI: https://doi.org/10.22487/ghidza.v5i1.247

\title{
Capaian Perkembangan Kognitif Anak Stunted dan Normal di TK/KB
}

\author{
Besse Nirmala $*^{1}$ \\ ${ }^{1}$ Program Studi PG PAUD, FKIP, Universitas Tadulako, Palu, Indonesia \\ Author's Email Correspondence (*): bessenirmala @ rocketmail.com \\ (085242282284)
}

\begin{abstract}
Abstrak
Anak pendek atau stunting, merupakan kondisi gagal tumbuh pada anak yang terjadi sejak bayi dalam kandungan dan pada masa awal setelah bayi lahir. Akan tetapi, kondisi stunting baru nampak setelah bayi berusia dua tahun akibat dari kekurangan gizi kronis sehingga anak terlalu pendek untuk usianya. Kasus stunting ditemukan di Sulawesi Tengah khususnya di Kecamatan Palu Utara. Pendidikan Anak Usia Dini (PAUD) memiliki peran penting dalam berkontribusi mengantisipasi dan menurunkan tingkat stunting pada anak. Data kesehatan anak pada lembaga PAUD, khususnya tinggi badan, berat badan dan lingkar kepala anak, umumnya hanya dicatat tanpa dianalisis maupun dimanfaatkan untuk dimensi layanan kesehatan dan gizi dalam program Holistik Integratif (HI). Keterlibatan PAUD menghadapi fenomena stunting pada anak di Indonesia dapat dilakukan melalui penerapan PAUD berbasis HI secara maksimal. Penelitian ini bertujuan untuk mengetahui capaian perkembangan kognitif pada anak yang stunting dan normal. Kriteria stunting ditentukan berdasarkan indeks TB/U <-2 SD. Penelitian ini melibatkan 134 anak TK di Kecamatan Palu Utara. Analisis data dilakukan melalui analisis univariat untuk melihat distribusi frekuensi dan bivariat untuk melihat hubungan antar variabel. Hasil penelitian menunjukkan bahwa terdapat 13 orang anak $(9,7 \%)$ mengalami stunting dan terdapat 121 orang anak $(91,3 \%)$ dalam kategori normal. Dilihat dari pencapaian perkembangan kognitif anak stunting, 5,2\% belum berkembang dan 5,7\% mulai berkembang. Berdasarkan hasil penelitian tersebut dapat disimpulkan bahwa ada hubungan antara kejadian stunting dengan capaian perkembangan kognitif anak usia dini.
\end{abstract}

Kata Kunci: Capaian kognitif, Stunting, Normal, Anak Usia Dini

How to Cite:

Nirmala, B. (2021). Capaian Perkembangan Kognitif Anak Stunted dan Normal di TK/KB. Ghidza: Jurnal Gizi Dan Kesehatan, 5(1), 63 - 71. https://doi.org/10.22487/ghidza.v5i1.247

Published by:

Article history:

Tadulako University

Received : 29042021

Address:

Received in revised form : 07062021

Soekarno Hatta KM 9. Kota Palu, Sulawesi Tengah,

Accepted : 11062021

Indonesia.

Available online 07072021

Phone: +628525357076

Email: ghidzajurnal@gmail.com 


\begin{abstract}
Short children or stunting, is a condition of failure to thrive in children that occurs since the baby is in the womb and in the early days after the baby is born. However, the stunting condition only appears after the baby is two years old due to chronic malnutrition so that the child is too short for his age. Stunting cases were found in Central Sulawesi, especially in North Palu District. Early Childhood Education (ECE) has an important role in contributing to anticipating and reducing stunting rates in children. Data on children's health at ECE institutions, especially children's height, weight and head circumference, are generally only recorded without being analyzed or used for the dimensions of health and nutrition services in the Holistic Integrative (HI) program. The involvement of ECE in dealing with the phenomenon of stunting in children in Indonesia can be done through the maximum application of HIbased ECE. This study aims to determine the achievement of cognitive development in stunted and normal children. The stunting criteria were determined based on the TB/U index <-2 SD. This study involved 134 kindergarten children in North Palu District. Data analysis was carried out through univariate analysis to see the frequency distribution and bivariate to see the relationship between variables. The results showed that there were 13 children $(9.7 \%)$ were stunted and there were 121 children $(91.3 \%)$ in the normal category. Judging from the achievement of cognitive development of stunted children, 5.2\% have not developed and $5.7 \%$ are starting to develop. Based on the results of this study, it can be concluded that there is a relationship between the incidence of stunting and the achievement of early childhood cognitive development.
\end{abstract}

Keywords: Cognitive development, Stunted, Normal, Kindergarten

\title{
I. PENDAHULUAN
}

Kejadian stunting merupakan masalah gizi utama yang dihadapi di Indonesia. Berdasarkan data Pemantauan Status Gizi (PSG) selama tiga tahun terakhir, prevelensi balita pendek cenderung statis. Hasil Riset Kesehatan Dasar (Riskesdas) tahun 2007 menunjukkan prevelensi balita pendek di Indonesia sebesar 36,8\%. Pada tahun 2010, terjadi sedikit penurunan menjadi 35,6\%. Namun, prevelensi balita pendek kembali meningkat pada tahun 2013 yaitu menjadi 37,2\% (KemenKes, 2018). Gizi kurang dapat menyebabkan perkembangan kognitif atau kecerdasan, fisik motorik, dan bahasa berkembang secara tidak optimal. Selain itu, dapat mengganggu motivasi belajar anak, kemampuan untuk berkonsentrasi dan mudah jenuh. Anak yang memiliki tingkat kecerdasan yang tidak maksimal akibat stunting pada akhirnya akan menghambat pertumbuhan ekonomi dan meningkatkan kemiskinan (WHO, 2007). Kejadian stunting ini dapat diidentifikasi lebih awal ketika anak berada di lembaga TK/KB.

Berdasarkan data Tahun 2018, Kota Palu memiliki 678 guru, 145 TK/KB, dan 3.985 anak (Hidayat, 2019). Satuan PAUD merupakan jenjang pendidikan yang memiliki ragam program layanan antara lain: TPA (Taman Penitipan Anak)/Daycare, KB (Kelompok Bermain)/Playgroup, TK (Taman Kanak- kanak), dan sebagainya. Semua program tersebut merupakan layanan yang sangat mungkin untuk dapat menstimulasi secara optimal bagi anak sejak lahir sampai dengan usia enam tahun. Oleh sebab itu, PAUD memiliki peran penting dalam berkontribusi, mengantisipasi dan menurunkan tingkat stunting pada anak balita sehingga dapat tercapai target Sustainable Development Goals (SDGs) pada tahun 2025 yaitu penurunan angka stunting hingga 40\% (Vallery, 2020).

Anak pendek atau stunting adalah kondisi gagal tumbuh pada anak balita (bayi di bawah lima tahun) akibat dari kekurangan gizi kronis sehingga anak terlalu pendek untuk usianya (Mitra, 2015). Kekurangan gizi terjadi sejak bayi dalam kandungan dan pada masa awal setelah bayi lahir 
akan tetapi, kondisi stunting baru nampak setelah bayi berusia 2 tahun (Budi, 2018). Balita pendek (stunted) dan sangat pendek (severely stunted) adalah balita dengan panjang badan ( $\mathrm{PB} / \mathrm{U})$ atau tinggi badan (TB/U) menurut umurnya dibandingkan dengan standar baku WHO-MGRS (Multicentre Growth Reference Study) (WHO, 2006; WHO, 2007).

Stunting pada anak dapat berakibat fatal terhadap produktivitas anak di masa dewasa. Anak stunting akan mengalami kesulitan dalam belajar dibandingkan anak normal. Anak yang mengalami stunting memiliki potensi tumbuh kembang yang tidak sempurna, kemampuan motorik, dan produktivitas rendah, serta memiliki resiko lebih tinggi untuk menderita penyakit menular (Widanti, 2017). Stunting merupakan gangguan pertumbuhan yang dapat mengindikasikan adanya gangguan pada organ-organ tubuh. Salah satu organ yang paling cepat mengalami kerusakan pada kondisi gangguan gizi adalah otak. Otak merupakan pusat syaraf yang sangat berkaitan dengan respon anak untuk melihat, mendengar, berpikir, dan melakukan gerakan (Picauly \& Toy, 2013). Perkembangan kognitif menurut (Sujiono \& Zainal, 2007) yaitu perubahan yang terjadi dalam berpikir, kecerdasan dan bahasa anak untuk memberikan alasan sehingga anak dapat mengingat, menyusun strategi secara kreatif, berpikir melalui pemecahan masalah dan dapat menghubungkan kalimat menjadi pembicaraan yang bermakna (Retnaningrum, 2016).

Menurut (Sujiono \& Zainal, 2007), perkembangan kognitif sangat penting dan sangat diperlukan bagi anak karena: 1) mengembangkan daya persepsi anak berdasarkan apa yang dilihat, didengar, dan dirasakan agar anak dapat memahami dan menerima dengan baik, 2) melatih ingatannya pada peristiwa dan kejadian yang pernah dialami anak, 3) mengembangkan pemikirannya untuk menghubungkan satu peristiwa dengan peristiwa yang lain, 4) menalar apa yang sedang terjadi baik proses alamiah maupun proses ilmiah (percobaan), 5) memecahkan persoalan hidup yang diharapinya agar dapat menolong dirinya sendiri, dan 6) memahami berbagai simbol yang tersebar di lingkungan sekitarnya. Keterlibatan PAUD menghadapi fenomena stunting pada anak di Indonesia dapat melalui penerapan PAUD berbasis Holistik Integratif (HI) secara maksimal. Tujuan dari penelitian ini yaitu untuk menganalisis capaian perkembangan kognitif anak stunted dan normal di TK/KB Kecamatan Palu Utara.

\section{METODE}

Jenis penelitian ini adalah survey. Desain yang digunakan dalam penelitian ini yaitu analitik korelasi dengan pendekatan cross-sectional. Penelitian ini dilaksanakan pada bulan Mei sampai September 2020 di TK/KB Kecamatan Palu Utara. Adapun TK yang dilibatkan dalam penelitian ini yaitu: TK TK Negeri Pembina Palu Utara, TK KT II Mamboro, TK KT Watuoge, TK Aisyiyah BA Mamboro, dan TK Alkhairaat Kayumalue Ngapa.

Jumlah TK/KB di Kecamatan Palu Utara Kota Palu sebanyak 32 lembaga. Teknik penarikan sampel dipilih secara purposive sampling dengan kriteria yaitu: 1) berusia 4-6 tahun; 2) memiliki orang tua lengkap dan bersedia diambil datanya; 3 ) mempunyai data berat badan dan panjang badan saat lahir; dan 4) tidak mempunyai kelainan bawaan. Sampel penelitian ini yaitu anak yang mengalami stunting dan 
yang tidak mengalami stunting yang ada di TK/KB wilayah Kecamatan Palu Utara. Jumlah sampel yang berhasil diteliti yaitu 134 orang anak yang berasal dari lima lembaga TK/KB.

Pengumpulan data primer melalui survey dan observasi langsung, serta data sekunder diperoleh dari instansi terkait. Data variabel dependen yakni capaian perkembangan kognitif anak dan juga catatan hasil pengukuran tinggi badan, berat badan dan lingkar kepala anak diperoleh lima TK/KB di Kecamatan Palu Utara, kemudian dianalisis dengan menggunakan standar kesehatan dan gizi dari WHO.

Analisis data yang akan dilaksanakan adalah analisis univariat terhadap variabel independen dan dependen. Bentuk rerata dengan standar deviasi dan bivariate untuk melihat hubungan antara variabel independen dengan dependen dengan uji kemaknaan chi square. Derajat kepercayaan penelitian ini sebesar 95\%. Bila hasilnya tidak memenuhi syarat chi square maka dilakukan uji alternatif menggunakan uji Fisher (Priyatno, 2010).

\section{HASIL}

Capaian perkembangan kognitif anak diperoleh dari hasil observasi perkembangan kognitif anak yang dikumpulkan melalui link google form yang dapat diakses oleh guru. Link instrumen dalam penelitian ini dapat diakses pada https://bit.ly/30rue5F.

\section{Karakteristik Responden}

Berdasarkan data tersebut, jumlah sampel dalam penelitian ini yaitu sebanyak 134 orang anak yang tersebar dalam 5 TK/KB yang ada di Kecamatan Palu Utara. Peneliti mengidentifikasi anak yang menjadi subjek penelitian berdasarkan usia dan jenis kelamin dari lima lembaga TK/KB yang ada di Kecamatan Palu Utara. Adapun karakteristik responden berdasarkan usia dan jenis kelamin yaitu sebagai berikut.

Tabel 1. Karakteristik Responden Berdasarkan Usia

\begin{tabular}{|c|c|c|c|c|c|c|}
\hline \multirow{2}{*}{ Lembaga PAUD (Instansi) } & \multicolumn{2}{|c|}{$4-5$ tahun } & \multicolumn{2}{|c|}{ 5-6 tahun } & \multirow{2}{*}{$\begin{array}{l}\text { Total } \\
\text { (N) }\end{array}$} & \multirow[t]{2}{*}{$\%$} \\
\hline & f & $\%$ & $\mathrm{~N}$ & $\%$ & & \\
\hline TK Negeri Pembina Palu Utara & 16 & 11,9 & 24 & 17,9 & 40 & 29,9 \\
\hline TK KT II Mamboro & 12 & 9,0 & 10 & 7,5 & 22 & 16,4 \\
\hline TK KT Watuoge & 8 & 6,0 & 12 & 9,0 & 20 & 14,9 \\
\hline TK Aisyiyah BA Mamboro & 11 & 8,2 & 15 & 11,2 & 26 & 19,4 \\
\hline TK Alkhairaat Kayumalue Ngapa & 10 & 7,5 & 16 & 11,9 & 26 & 19,4 \\
\hline Total & 57 & 42,5 & 71 & 57,5 & 134 & 100 \\
\hline
\end{tabular}

(Sumber: Data Primer, 2020)

Berdasarkan tabel di atas, jumlah anak yang berusia 4-5 tahun yaitu sebanyak 57 orang anak (42,5\%) dan 5-6 tahun yaitu sebanyak 71 orang anak (57,5\%). Sampel yang paling banyak yaitu di TK Negeri Pembina Palu Utara sebanyak 40 orang anak $(29,9 \%)$ dan sampel yang paling sedikit di TK KT Watuoge sebanyak 20 orang anak (14,9\%).

\section{Status Gizi Anak}

Status gizi anak dinilai berdasarkan indeks antropometri stunting. Adapun hasil analisis kejadian stunting anak usia dini dapat dilihat pada tabel di bawah ini. 
Tabel 2. Status Gizi Responden

(Sumber: Data Primer, 2020)

\begin{tabular}{cccc}
\hline No. & Kategori & Frekuensi & Persentase (\%) \\
\hline 1 & Stunting & 13 & 9,7 \\
\hline 2 & Tidak Stunting & 121 & 90,3 \\
\hline & Total & 134 & 100 \\
\hline
\end{tabular}

Berdasarkan tabel di atas, terdapat 13 orang anak $(9,7 \%)$ dengan status stunting, dan terdapat 121 orang anak (90,3\%) dengan status tidak stunting. Setelah menetapkan status gizi anak, tim peneliti selanjutnya melakukan observasi terhadap capaian perkembangan kognitif anak dengan mengacu pada Standar Tingkat Pencapaian Perkembangan Anak pada Permen 137 tahun 2014 yang kemudian dikembangkan oleh tim peneliti. Data capaian perkembangan anak mengacu pada teknik analisis dari Mendiknas dengan empat kategori yaitu: Berkembang Sangat Baik (BSB), Berkembang Sesuai Harapan (BSH), Mulai Berkembang (MB), dan Belum Berkembang (BB). Adapun hasil observasi terhadap capaian perkembangan kognitif anak dapat dilihat pada tabel di bawah ini.

Tabel 3. Capaian Perkembangan Kognitif Anak

\begin{tabular}{clcc}
\hline No. & \multicolumn{1}{c}{ Kategori Capaian } & Frekuensi & Persentase (\%) \\
\hline 1 & Berkembang Sangat Baik (BSB) & 39 & 29,1 \\
\hline 2 & Berkembang Sesuai Harapan (BSH) & 60 & 44.7 \\
\hline 3 & Mulai Berkembang (MB) & 24 & 17.9 \\
\hline 4 & Belum Berkembang (BB) & 11 & 8.3 \\
\hline & Total & 134 & 100 \\
\hline
\end{tabular}

(Sumber: Data Primer, 2020)

Berdasarkan tabel di atas, terdapat 39 orang anak $(29,1 \%)$ capaian perkembangan kognitif dengan kategori berkembang sangat baik, 60 orang anak (44,7\%) dengan kategori berkembang sesuai harapan, 24 orang anak (17,9\%) dengan kategori mulai berkembang, dan 11 orang anak $(8,3 \%)$ dengan kategori belum berkembang. Selanjutnya, peneliti melakukan analisis dengan menggunakan tabulasi silang kejadian stunting dengan capaian perkembangan kognitif anak usia dini. Adapun tabulasi silang dapat dilihat pada tabel di bawah ini.

Tabel 4. Tabulasi Silang Kejadian Stunting dengan Capaian Perkembangan Kognitif

\begin{tabular}{lcccccc}
\hline \multirow{2}{*}{\multicolumn{1}{c}{ Capaian Kognitif }} & \multicolumn{2}{c}{ Stunting } & \multicolumn{2}{c}{ Tidak Stunting } & \multicolumn{2}{c}{ Total (\%) } \\
\cline { 2 - 7 } & $f$ & $\%$ & $f$ & $\%$ & $f$ & $\%$ \\
\hline Belum Berkembang (BB) & 9 & 6.8 & 2 & 1.5 & 11 & 8.3 \\
\hline Mulai Berkembang (MB) & 3 & 2.2 & 21 & 15.7 & 24 & 17.9 \\
\hline Berkembang Sesuai Harapan (BSH) & 1 & 0.7 & 59 & 44.0 & 60 & 44.7 \\
\hline Berkembang Sangat Baik (BSB) & 0 & 0.0 & 39 & 29.1 & 39 & 29.1 \\
\hline \multicolumn{1}{c}{ Total } & 13 & 9.7 & 121 & 90.3 & 134 & 100 \\
\hline
\end{tabular}

(Sumber: Data Primer, 2020)

Berdasarkan tabel di atas dapat diketahui bahwa dari 13 orang anak yang mengalami kejadian stunting terdapat 1 orang anak $(0,7 \%)$ yang capaian perkembangan kognitif dengan kategori berkembang 
sesuai harapan, 3 orang anak (2,2\%) dengan kategori mulai berkembang, dan 9 orang anak (6,8\%) dengan kategori belum berkembang. Sedangkan anak yang tidak mengalami stunting terdapat 121 orang dimana 39 orang anak $(29,1 \%)$ yang capaian perkembangan kognitif anak berada pada kategori berkembang sangat baik, 59 orang anak (44,0\%) dengan kategori berkembang sesuai harapan, 21 orang anak $(15,7 \%)$ dengan kategori mulai berkembang, dan 2 orang anak $(1,5 \%)$ dengan kategori belum berkembang.

Selanjutnya, peneliti menganalisis hubungan antara kejadian stunting dengan capaian perkembangan kognitif anak dengan menggunakan rumus korelasi Chi-Square. Pengujian ini dilakukan untuk menguji hipotesis pada penelitian ini yaitu "ada hubungan antara kejadian stunting dengan capaian perkembangan kognitif anak usia dini di TK/KB Kecamatan Palu Utara. Hasil uji hipotesis menunjukkan dinilai $X^{2 \text { hitung }}=73,299$ dengan $\mathrm{df}=3$ dan $\alpha=0,05$ (5\%). Kedua variabel dikatakan mempunyai hubungan jika nilai $X^{2 \text { hitung }}>X^{\text {2tabel }}$ serta nilai Sig. $<\alpha=0,05$, dapat diketahui bahwa nilai $X^{2 \text { tabel }}$ adalah 7,815. Hasil analisis menunjukkan bahwa $X^{\text {2hitung }}(73,299)>X^{2 \text { tabel }}(7,815)$ serta nilai Asymp. Sig (2-sides) yaitu $(0,000)<\alpha(0,05)$, maka berdasarkan dasar pengambilan keputusan di atas, dapat disimpulkan bahwa Ho ditolak dan Ha diterima. Dengan demikian dapat diartikan bahwa "ada hubungan antara kejadian stunting dengan capaian perkembangan kognitif anak usia dini TK/KB di Kecamatan Palu Utara". Nilai $\mathrm{X}^{\text {2hitung }}$ sebesar 73,299 adalah positif (+), yang menunjukkan bahwa kedua variabel penelitian mempunyai hubungan yang berbanding lurus, atau jika salah satu variabel mengalami peningkatan, maka variabel satunya cenderung juga akan mengalami peningkatan.

\section{PEMBAHASAN}

Perkembangan kognitif adalah pengembangan keterampilan berpikir yaitu perhatian, ingatan, penalaran, bahasa, kreativitas, dan imajinasi (Papalia et al., 2007). Anak-anak yang mendapatkan stimulasi yang tepat dan tepat sasaran akan mengembangkan aspek kognitifnya lebih cepat dibandingkan dengan anak yang tidak mendapat stimulasi dengan baik. Penelitian di Belanda menunjukkan bahwa anak-anak yang dirangsang sejak usia dini di Taman Perawatan Anak akan mengembangkan perkembangan kognitif, sosial emosional, dan bahasa yang lebih baik (Albers et al., 2010).

Berdasarkan hasil penelitian dapat diketahui bahwa kejadian stunting pada anak usia 4-6 tahun di Taman Kanak-kanak/KB di Kecamatan Palu Utara sebanyak 13 anak (9,7\%). Sedangkan yang tidak stunting ada 121 anak (90,3\%). Analisis bivariat status gizi TB/U dengan perkembangan kognitif anak usia dini di Kota Palu memiliki hubungan yang signifikan dan cenderung anak dengan perkembangan kognitif kurang berkembang lebih cenderung berada pada kelompok stunting. Hasil ini sesuai dengan hasil penelitian Warsito (Warsito et al., 2012) tentang status gizi dengan indeks TB/U yang mempunyai implikasi signifikan terhadap pencapaian perkembangan kognitif anak.

Hasil penelitian dari Ajayi, Matthews, Taylor, dan Darcel (Ajayi et al., 2017) menyatakan bahwa anak yang mengalami stunting akan berdampak pada penurunan kinerja sistem syaraf dan berimplikasi pada rendahnya kemampuan kognitif anak. Ada beberapa faktor yang berkaitan dengan capaian perkembangan kognitif anak meliputi faktor internal dan eksternal. Faktor internal yang mempengaruhi perkembangan kognitif anak yaitu jenis kelamin dan usia anak. Hasil penelitian terdahulu menyatakan 
bahwa jenis kelamin anak berpengaruh pada perkembangan kognitif anak (Galván et al., 2013) dan usia anak berpengaruh terhadap kognitif anak (Lynch \& Gibbs, 2017). Faktor eksternal diantaranya yaitu karakteristik keluarga.

Menurut Dickerson dan Popli (Dickerson \& Popli, 2016), peran latar belakang keluarga sebagai penentu tumbuh kembang anak dimulai dari usia sebelum lima tahun pertama sampai dewasa. Kejadian stunting pada anak di Kecamatan Palu Utara didominasi oleh keluarga dengan tingkat kesejahteraan keluarga yang rendah, dimana sebagian orang tua anak bekerja sebagai nelayan, buruh, dan wiraswasta. Menurut Chang (Chang et al., 2010) anak usia dini yang mengalami kejadian stunting mendapatkan skor yang lebih rendah dibandingkan dengan anak yang tidak stunting terlepas dari latar belakang pendidikan, ekonomi, dan sosial keluarganya.

Penelitian Kar et al. (Solihin et al., 2013) mengemukakan bahwa anak yang kekurangan gizi tercermin dalam keadaan stunting memiliki masalah pada pemusatan perhatian, memori, pembelajaran dan kemampuan visiospasial. Kejadian stunting ini tidak hanya berpengaruh pada perkembangan kognitif, akan tetapi juga berpengaruh pada tahap yang lebih tinggi sehingga menghasilkan gangguan kognitif untuk jangka panjang. Hal ini juga dijelaskan oleh Yadika bahwa keadaan kurang gizi yang yang lebih berat dan kronis tidak hanya mengganggu pertumbuhan, tetapi juga menyebabkan jumlah sel dalam otak berkurang dan terjadi ketidakmatangan serta ketidaksempurnaan organisasi biokimia dalam otak. Keadaan ini akan berpengaruh terhadap perkembangan kecerdasan anak (Yadika et al., 2019).

\section{KESIMPULAN}

Hasil penelitian ini menunjukkan bahwa anak usia dini di TK/KB Kecamatan Palu Utara terdapat 13 anak $(9,7 \%)$ yang mengalami kejadian stunting. Hasil analisis disimpulkan bahwa ada hubungan antara kejadian stunting dengan capaian perkembangan kognitif anak usia dini. Temuan ini mengindikasikan pentingnya sosialisasi pencegahan stunting pada lembaga-lembaga PAUD yang ada di Kecamatan Palu Utara. Perlu ada kerja sama antara guru dan orang tua dalam pemenuhan gizi yang sehat dan seimbang serta stimulasi sejak dini untuk mendukung capaian perkembangan kognitif pada anak di masa akan datang. Penyelenggaraan PAUD HI perlu segera dilaksanakan sebagai upaya preventif yang mampu menekan resiko kejadian stunting pada generasi masa depan.

\section{UCAPAN TERIMA KASIH}

Penelitian ini didanai oleh DIPA Fakultas Keguruan dan Ilmu Pendidikan Universitas Tadulako tahun 2020. Terima kasih penulis sampaikan kepada pimpinan Fakultas Keguruan dan Ilmu Pendidikan serta Lembaga Penelitian dan Pengabdian Kepada Masyarakat Universitas Tadulako yang telah menyetujui usulan penelitian ini. 


\section{DAFTAR PUSTAKA}

Ajayi, O. R., Matthews, G. B., Taylor, M., Kvalsvig, J. D., Davidson, L., Kauchali, S., \& Mellins, C. (2017). Structural equation modeling of the effects of family, preschool, and stunting on the cognitive development of school children. Frontiers in Nutrition, 4(1-12), 17. https://doi.org/https://doi.org/10.3389/fnut.2017.00017

Albers, E. M., Riksen-Walraven, J. M., \& de Weerth, C. (2010). Developmental stimulation in child care centers contributes to young infants' cognitive development. Infant Behavior and Development, 33(4), 401-408.

Budi, S. (2018). Faktor-Faktor Penyebab Stunting Pada Anak Usia Dini. Bekasi: Yayasan Rumah Komunitas Kreatif.

Chang, S. M., Walker, S. P., GRANTHAM-MCGREGOR, S., \& Powell, C. A. (2010). Early childhood stunting and later fine motor abilities. Developmental Medicine \& Child Neurology, 52(9), 831-836.

Dickerson, A., \& Popli, G. K. (2016). Persistent poverty and children's cognitive development: evidence from the UK Millennium Cohort Study. Journal of the Royal Statistical Society. Series A (Statistics in Society), 535-558.

Galván, M., Uauy, R., Corvalán, C., López-Rodríguez, G., \& Kain, J. (2013). Determinants of cognitive development of low SES children in Chile: a post-transitional country with rising childhood obesity rates. Maternal and Child Health Journal, 17(7), 1243-1251. https://doi.org/https://doi.org/10.1016/j.jpeds.2013.10.015

Hidayat, D. (2019). Data dan Informasi Kemiskinan Kabupaten/Kota Tahun 2015. Jakarta: Badan Pusat Statistik.

KemenKes, R. (2018). Hasil utama RISKESDAS 2018. Jakarta: Kementerian Kesehatan Badan Penelitian Dan Pengembangan Kesehatan.

Lynch, J. L., \& Gibbs, B. G. (2017). Birth weight and early cognitive skills: Can parenting offset the link? Maternal and Child Health Journal, 21(1), 156-167. https://doi.org/https://doi.org/10.1007/s10995016-2104

Mitra, M. (2015). Permasalahan Anak Pendek (Stunting) dan Intervensi untuk Mencegah Terjadinya Stunting (Suatu Kajian Kepustakaan). Jurnal Kesehatan Komunitas, 2(6), 254-261.

Papalia, D. E., Sterns, H. L., Feldman, R. D., \& Camp, C. J. (2007). Adult development and aging. McGraw-Hill.

Picauly, I., \& Toy, S. M. (2013). Analisis determinan dan pengaruh stunting terhadap prestasi belajar anak sekolah di Kupang dan Sumba Timur, NTT. Jurnal Gizi Dan Pangan, 8(1), 55-62.

Priyatno, D. (2010). Teknik mudah dan cepat melakukan analisis data penelitian dengan SPSS dan tanya jawab ujian pendadaran. Yogyakarta: Gaya Media, 1.

Retnaningrum, W. (2016). Peningkatan perkembangan kognitif anak usia dini melalui media bermain memancing. JPPM (Jurnal Pendidikan Dan Pemberdayaan Masyarakat), 3(2), 207-218.

Solihin, R. D. M., Anwar, F., \& Sukandar, D. (2013). Kaitan antara status gizi, perkembangan kognitif, dan perkembangan motorik pada anak usia prasekolah (relationship between nutritional status, 
cognitive development, and motor development in preschool children). Nutrition and Food Research, 36(1), 62-72.

Sujiono, Y. N., \& Zainal, O. R. (2007). Metode pengembangan kognitif. Jakarta: Universitas Terbuka.

Vallery, H. (2020). Implementasi sustainable development goals (SDGs) di Indonesia selama pemerintahan Presiden Joko Widodo periode 2015-2019= Implementation of sustainable development goals (SDGs) in Indonesia throughout the president Joko Widodo regime period 2015 2019. Universitas Pelita Harapan.

Warsito, O., Khomsan, A., Hernawati, N., \& Anwar, F. (2012). Relationship between nutritional status, psychosocial stimulation, and cognitive development in preschool children in Indonesia. Nutrition Research and Practice, 6(5), 451.

WHO. (2006). WHO child growth standards: length/height-for-age, weight-for-age, weight-for-length, weight-for-height and body mass index-for-age: methods and development. World Health Organization.

WHO. (2007). WHO child growth standards: head circumference-for-age, arm circumference-for-age, triceps skinfold-for-age and subscapular skinfold-for-age: methods and development. World Health Organization.

Widanti, Y. A. (2017). Prevalensi, faktor risiko, dan dampak stunting pada anak usia sekolah. JITIPARI (Jurnal Ilmiah Teknologi Dan Industri Pangan UNISRI), 1(1).

Yadika, A. D. N., Berawi, K. N., \& Nasution, S. H. (2019). Pengaruh stunting terhadap perkembangan kognitif dan prestasi belajar. Jurnal Majority, 8(2), 273-282. 